\title{
Leaf trichomes of Portuguese Lavandula species: a comparative morphological study
}

M. R. Zuzarte*,** A. M. Dinis*,** J. Canhoto*,** and L. Salgueiro*

* CEF/Laboratório de Farmacognosia, Faculdade de Farmácia, Pólo das Ciências da Saúde, University of Coimbra, Azinhaga de S. Comba 3000-354, Portugal

** Departamento de Botânica, University of Coimbra, Calçada Martim de Freitas 3001-455, Portugal

mzuzarte@hotmail.com

Lavandula species are aromatic plants that produce and accumulate essential oils in different types of glandular trichomes. The oils protect the aerial parts of the plant against herbivores and pathogens, and are of great economic value for fragrance, pharmaceutical, food and flavour industries. In Portugal there are five spontaneous species of Lavandula which are included in three different sections: Section Lavandula (L. latifolia), Section Pterostoechas (L. multifida) and Section Stoechas (L. luisieri, L. pedunculata, L. viridis). Our preliminary observations showed that these species have a high diversity of trichomes. This, associated with the fact that trichome morphology is often referred as an useful characteristic for systematic purposes [1], led us to investigate leaf trichome morphology in the five Portuguese species, using scanning electron microscopy (SEM).

Samples of leaves were fixed in $2.5 \%$ glutaraldehyde in $0.1 \mathrm{M}$ cacodylate buffer, $\mathrm{pH} 7.2$, for $3 \mathrm{~h}$. Following rinsing in the same buffer, the samples were dehydrated in a graded acetone series, critical point dried and sputter coated with a $200 \AA$ layer of gold palladium. Observations were carried out in a JEOL JSM-5400 at $15 \mathrm{kV}$.

SEM examination showed a very heterogeneous leaf indumentum in all the lavender species which included ramified non-glandular and glandular trichomes of different types: peltate, capitate type I, capitate type II and "bifurcated glandular" trichomes. A mixed type of trichomes with characteristics of both non-glandular and glandular ones ("ramified mixed type") was also observed in L. multifida and L. pedunculata (Fig. 1). Peltate and capitate trichomes are characteristic of the Lamiaceae and occurred in all the species investigated. Nevertheless, a few differences concerning mainly the stalk length of the capitate type II trichomes (Fig. 2) and cell arrangement in the head of peltate trichomes were found (Fig. 3). L. multifida, L. pedunculata and L.viridis showed "bifurcated glandular" trichomes (Fig. 4) whereas ramified non-glandular trichomes were completely absent in L. viridis. This last type of trichomes was found in L. latifolia, L. lusieri, L. multifida and L. pedunculata, although with variations in number and distribution.

Our results showed a higher diversity of trichomes for Lavandula species than previously reported and also support the taxonomic value attributed to the morphology and distribution of these structures. Moreover, a transition from ramified non-glandular trichomes to "bifurcated glandular" trichomes seems to occur, particularly in the species of the Section Stoechas, as previously suggested by Suarez-Cervera and Seoane-Camba [2]. 


\section{References}

[1] L. Ascensão, in: A.C. Figueiredo, J.G. Barroso, L.G. Pedro (Eds.), Potencialidades e Aplicações das Plantas Aromáticas e Medicinais, Curso Teórico-Prático, Faculdade de Ciências da Universidade de Lisboa, Lisboa, 2006, p.19.

[2] M. Suarez-Cervera, J. Seoane-Camba, Biocosme Mésogeen 6 (1989) 21.
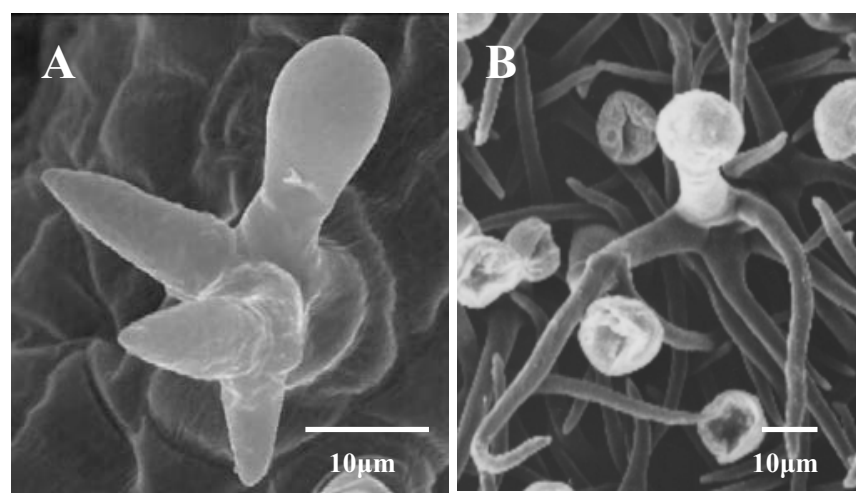

Fig. 1. "Ramified mixed type" trichomes, showing characteristics of both nonglandular and glandular trichomes. A. L. multifida. B. L. pedunculata.
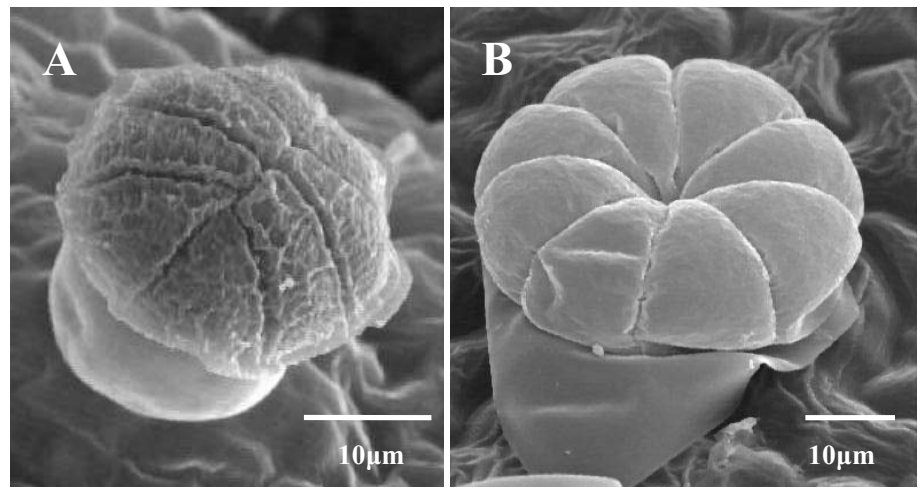

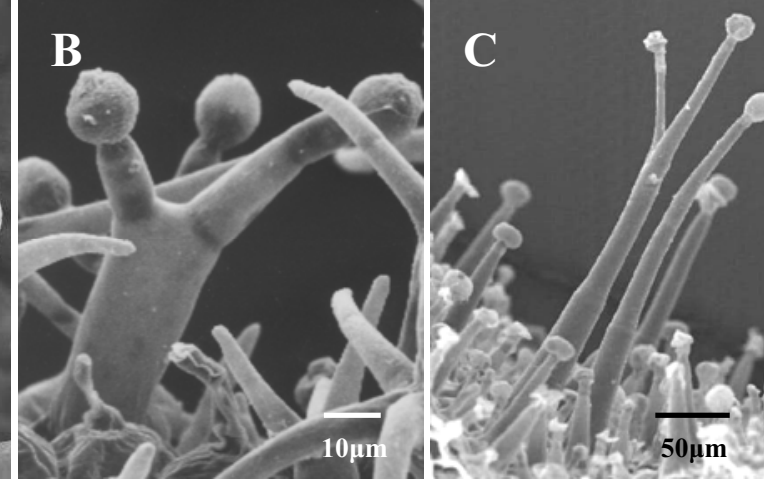

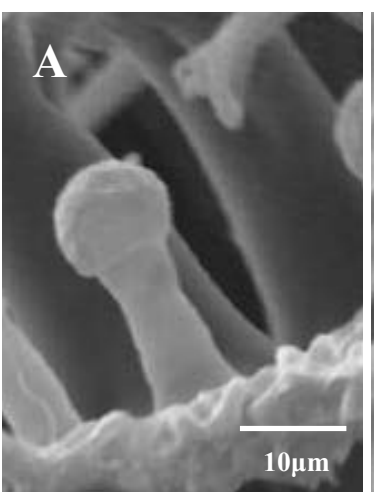

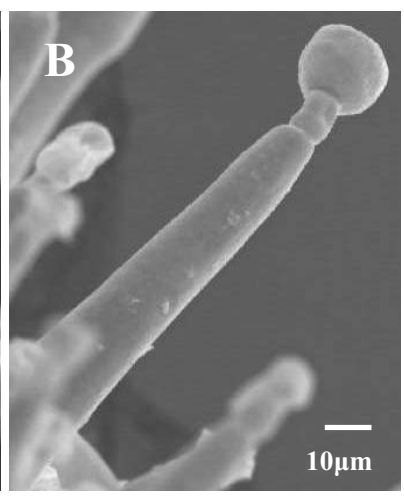

Fig. 2. Capitate type II trichomes, displaying differences in stalk lenght. A. L. luisieri. B. L. viridis.

Fig. 3. Arrangement of the eight secretory cells in the head of peltate trichomes. A. L. multifida with two rows of secretory cells. B. L. viridis with cells disposed in rosette.

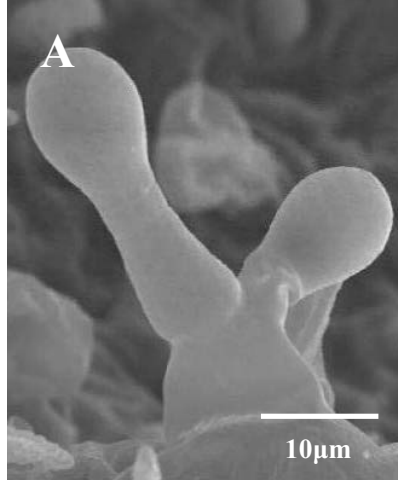

Fig. 4. "Bifurcated glandular" trichomes showing different stalk lenghts.
A. L. multifida.
B. L. pedunculata.
C. L.viridis. 